\title{
Paisagens produtivas como estratégia de sustentabilidade e segurança alimentar nas cidades
}

\author{
Alina Martins Costa Mesquita \\ Universidade Federal do Rio de Janeiro, Programa de Pós-Graduação em Planejamento Urbano e \\ Regional, Rio de Janeiro, RJ, Brasil. E-mail: alina_mesquita@ hotmail.com
}

Submetido em 20 de julho de 2019'. Aceito em 18 de dezembro de 2019.

\begin{abstract}
Resumo. A alimentação, apesar de um fator básico para a vida humana, não é tratada como uma questão relevante no planejamento urbano. A incorporação de espaços produtivos na cidade poderia trazer inúmeros benefícios ambientais, econômicos e sociais. Neste trabalho, através de revisão bibliográfica e documental, se apresentam reflexões para o planejamento e projeto de espaços públicos produtivos, experimentados através da proposição de um plano urbanístico para a cidade de Niterói. Esse plano se baseia no conceito de CPULs (Continuous Productive Urban Landscapes), que compreende a agricultura como infraestrutura essencial à vida urbana e também como elemento de paisagens produtivas que articulam múltiplos usos e funções, incitando novas práticas e relações sócio-espaciais. Por fim, se discute o papel de fatores-chave para a efetividade do planejamento proposto, como a participação da população e a articulação de políticas públicas multissetoriais para fortalecer os efeitos gerados por esses espaços.
\end{abstract}

Palavras-chave. agricultura urbana, paisagens produtivas, sustentabilidade, espaço público, infraestrutura verde.

\section{Introdução}

A alimentação é uma necessidade fundamental para a vida humana, o que não significou que esse tema ganhasse visibilidade e a devida importância dentro do planejamento e do desenho das cidades. Pelo contrário: com o planejamento moderno e o aprofundamento da divisão rural-urbano, a cidade foi cada vez mais concebida como um lugar sem espaço para práticas de cultivo agrícola, onde as áreas verdes são limitadas e as práticas espontâneas da população não são reconhecidas como formas relevantes de produção do espaço.

A Organização das Nações Unidas para a Alimentação e a Agricultura (FAO) estima que, atualmente, como resultado do alto custo dos alimentos, um bilhão de pessoas sofrem de fome crônica, sendo as mais afetadas as que vivem no meio urbano, por dependerem exclusivamente da compra de alimentos, e portanto, estarem vulneráveis às variações de preço. Outro estudo da FAO, de 2004, estima que o Brasil está entre os 10 países que mais desperdiçam comida, com uma perda de cerca de $35 \%$ da produção agrícola. Metade desse desperdício ocorre na fase de manuseio e transporte dos alimentos. O desperdício de alimentos perecíveis, como hortaliças e frutas, é ainda mais alarmante. Segundo a pesquisa da Embrapa realizada nas 10 principais capitais do país, o consumo anual de vegetais dos brasileiros é de $35 \mathrm{~kg} / \mathrm{hab}$, enquanto o desperdício chega a $37 \mathrm{~kg} / \mathrm{hab}$.

Recentemente, o tema da agricultura urbana aflora em discussões acadêmicas, no âmbito das políticas públicas e também na agenda das agências multilaterais de financiamento. Essa visibilidade decorre da sua potencialidade de articular e trazer ao debate diversos temas, como a questão ambiental nas cidades, a (in)segurança alimentar, $o$ entrave do acesso à terra urbana e a segregação socioespacial (Coutinho e Costa, 2012). A agricultura urbana também permite a revisão da dicotomia campo-cidade, possibilitando novos usos e novas relações no espaço urbano, além de suscitar a reflexão 
sobre modelos locais e mais sustentáveis de produção, processamento e distribuição de alimentos (local food systems).

Apesar de aparentemente um tema novo, a agricultura sempre esteve de alguma forma relacionada ao espaço urbano. A agricultura e a cidade ocidental sustentaram uma relação simbiótica rompida a partir da Revolução Industrial, que pressupunha a expansão acelerada e desordenada da cidade às custas de um espaço agrário considerado

dispensável (Alonso e Casadevante, 2014). A agricultura urbana posteriormente aparece de forma pontual em momentos de crises econômicas, conflitos bélicos, etc.

Historicamente as hortas urbanas cumprem um papel de resposta urgente frente às crises, em momentos nos quais o abastecimento de alimentos para as cidades se encontra extremamente comprometido. Porém a agricultura urbana poderia fazer parte de uma estratégia mais ampla, que busque reverter a insustentabilidade do modelo atual. Para Araújo e Machado (2018), a repercussão atual desse tema também se relaciona a um momento de crise, não apenas uma, mas diversas crises, como a ambiental, econômica, dos espaços urbanos, além do aumento da pobreza e da fome nas cidades.

A agricultura urbana, mesmo sem nenhum apoio governamental, é uma atividade que é e sempre foi praticada nas cidades, por isso, precisa ser compreendida como um elemento do planejamento e da estruturação do espaço urbano. Não integrar a agricultura formalmente à cidade é não reconhecer suas potencialidades, condenando que essa atividade continue enfrentando os conflitos, riscos e as inseguranças de permanecer no âmbito informal.

Partindo do princípio de que a alimentação é uma necessidade tão básica quanto o provimento de água ou abrigo, essa deveria ser abordada pelos planejadores e urbanistas como uma infraestrutura essencial nas cidades. Nesse sentido, o objetivo deste trabalho é refletir sobre a agricultura urbana enquanto política integrada ao planejamento e ao desenho urbano e desenvolver um exercício de experimentação através da proposição de uma plano para a cidade de Niterói inspirado pelo conceito de CPULs (Continuous Productive Urban Landscapes), possibilitando a reflexão acerca das potencialidades e dificuldades relacionadas à implementação de paisagens produtivas. $\mathrm{O}$ conceito de CPULs se caracteriza pela conexão de paisagens produtivas com áreas verdes, compreendendo os espaços de produção alimentar como infraestruturas essenciais à cidade, e que podem funcionar como paisagens multifuncionais e conectores urbanos.

A pesquisa se baseia em levantamento bibliográfico e documental para apresentação da agricultura urbana e do conceito de CPULs que baseia as propostas. Para a caracterização da agricultura urbana em Niterói, foram coletados dados junto aos órgãos municipais de Niterói responsáveis pela elaboração e gestão de projetos na área, envolvidos e pesquisadores da área. Foram consultadas legislações da cidade como o Plano Diretor, o Diagnóstico para Revisão do Plano Diretor, e os anais da $6^{\mathrm{a}}$ Conferência da Cidade de Niterói. Os dados coletados são utilizados como subsídio para o desenvolvimento de um Plano de CPULs para Niterói, representado por um mapa síntese da proposta.

\section{Agricultura Urbana: uma breve contextualização}

Segundo Santandreu e Lovo (2007), a Agricultura Urbana e Periurbana (AUP) é um conceito multidimensional que inclui a produção, o agro extrativismo e a coleta, a transformação e prestação de serviços de forma segura, para gerar produtos agrícolas e pecuários, voltados ao autoconsumo, trocas, doações ou comercialização, (re) aproveitando-se de forma eficiente e sustentável recursos e insumos locais (solo, água, resíduos sólidos, mão-de-obra, saberes). Essas atividades podem se localizar no espaço intra-urbano ou periurbano, se caracterizando principalmente pela integração e interação com o ecossistema urbano, sendo conectada ao tecido e à economia urbana.

A agricultura urbana surge no debate acadêmico e enquanto política pública de maneira relativamente recentemente. Ela não é, no entanto, uma prática propriamente nova. A agricultura sempre teve relações 
próximas com o meio urbano, apontadas como um fenômeno universal:

A análise histórica mostra que a agricultura urbana está presente nas sociedades humanas desde a sua origem. Isto permite dizer que trata-se de um fenômeno universal. As fontes histórico literárias, teórico políticas e filosóficas que descrevem o aparecimento das primeiras cidades, a sua estrutura e o seu funcionamento (Virgile: Les Géorgiques, Aristote: Politique, Fouquidide: Histoires), bem como os testemunhos da teoria da arquitetura (Vitruve: Tratado de Arquitetura) mostram uma estreita ligação entre o urbano e o rural na vida das pessoas. (Boukharaeva, Chianca e Marloie, 2007, p. 13)

No Brasil, a agricultura urbana tem seu desenvolvimento recente relacionado à modernização da agricultura, que provocou uma forte migração da população em direção às cidades e suas periferias a partir da década de 1940. Essa população, socialmente excluída, sofre com a violência, a miséria, e a degradação urbana e ambiental dos espaços que habita, recorrendo então, ao cultivo de alimentos para suplementar suas necessidades básicas.

Mais recentemente, verificamos que as práticas de fomento à agricultura urbana se baseiam na promoção do desenvolvimento local, integração social, melhoria dos hábitos alimentares, educação ambiental e melhoria da qualidade do ambiente urbano. Mesmo com o crescente interesse político pela agricultura urbana, isso não se traduziu, no entanto, a uma incorporação formal ao desenho e à gestão urbana na maioria das cidades. Essa incorporação poderia desempenhar um importante papel devido ao grande potencial de articulação das questões ambientais, sociais e econômicas. Além da atividade produtiva em si, os espaços de agricultura urbana podem desempenhar diversos benefícios ambientais e serviços ecossistêmicos, além de melhorar a qualidade do ambiente urbano.

Apesar dos inúmeros argumentos técnicos, persistem os obstáculos relacionados à incorporação de espaços livres produtivos nas cidades. Uma das razões é a existência de uma visão de que essa atividade produz menos retorno financeiro do que poderia ser comercialmente desenvolvido no espaço urbano, em decorrência do alto alto custo da terra urbanizada. Por outro lado, é necessário reconhecer a necessidade de implantação de áreas livres para melhorar o ambiente urbano e consequentemente a vida da população. Alguns problemas enfrentados atualmente enfatizam a necessidade de se pensar sobre esse tema, como por exemplo: a degradação ambiental, a falta de áreas verdes, a fragilidade e os custos do sistema de produção e distribuição de alimentos para as cidades, a exclusão social, os espaços residuais subutilizados. Além disso, por ser uma prática com pouca ou nenhuma regulamentação nem acompanhamento técnico, apresenta diversos riscos como a contaminação do meio ambiente e dos alimentos, ao se utilizar indevidamente produtos químicos ou águas contaminadas para irrigação.

Do ponto de vista da sustentabilidade ambiental e urbana, a agricultura urbana pode gerar inúmeros benefícios, como maior permeabilidade do solo, conservação e geração de biodiversidade e melhora do microclima. A integração de paisagens produtivas com a gestão de águas pluviais também constitui uma importante possibilidade projetual para reduzir o risco de enchentes, a sobrecarga na rede de drenagem pluvial e a poluição difusa das águas.

As áreas de cultivo de alimentos podem ser incorporadas a outros espaços, com foco na multifuncionalidade e diversidade de usos. Por exemplo, podem se articular à infraestrutura verde, áreas verdes, outros equipamentos e espaços públicos educacionais, comunitários e de lazer, contribuindo para a sensibilização em torno de questões relativas ao meio ambiente e à alimentação. Além disso, a multifuncionalidade e articulação dos espaços produtivos com outros elementos permite a redução dos custos de manutenção relacionados às áreas verdes.

Outra possibilidade importante é a de aproveitamento de resíduos como lixo orgânico e esgoto doméstico, com o devido tratamento e regulamentação para não 
oferecer riscos aos produtores nem de contaminação do solo e dos alimentos. No contexto brasileiro, onde o esgoto de apenas $55 \%$ da população possui tratamento adequado $^{2}$, o aproveitamento das águas residuais também pode constituir uma importante estratégia para a sustentabilidade e resiliência urbana e ambiental, conscientização e educação ambiental.

Benefícios importantes são gerados também do ponto de vista social. A agricultura urbana pode contribuir na promoção da inclusão social, gerando empregos e renda, e promovendo a autonomia, bem como pode contribuir na criação de espaços que produzem outras sociabilidades, na valorização das práticas e costumes de uma determinada localidade, no acesso a alimentos frescos e mais baratos. Além disso, a agricultura urbana contribui no sentido de pensar a cidade fora da divisão rural-urbano, o que significa gerar novas possibilidades de relações socioespaciais.

Do ponto de vista econômico, podemos citar o estímulo da economia local, com a criação de empregos, feiras e eventos locais para venda da produção. $\mathrm{O}$ uso de terrenos ociosos públicos pode contribuir para diminuir gastos da prefeitura com limpeza e manutenção. Além disso, a agricultura urbana se insere como um importante elemento no desenvolvimento dos sistemas locais alimentares nas cidades, que geram menos custos de armazenamento e distribuição de alimentos, menos desperdício, e possibilitando a valorização de hábitos alimentares locais.

Os sistemas locais alimentares (local food systems) se caracterizam pelo alimento ser produzido, processado e vendido numa área geográfica delimitada. Essa organização da produção de alimentos forma um sistema mais resiliente, cooperativo e autônomo frente ao atual, gerando mais empregos numa comunidade, alimentos menos processados e mais saudáveis, além de permitir o aprendizado e a interação em torno dos alimentos e diminuir o desperdício e os custos ambientais e econômicos relacionados ao transporte e armazenamento da produção.

\section{O conceito de Continuous Productive Urban Landscapes - CPULs}

Com a intenção de integrar a produção de alimentos ao planejamento e ao desenho urbano, os arquitetos Katrin Bohn e Andre Viljoen desenvolveram o conceito de CPULs - Continuous Productive Urban Landscapes, explorando principalmente a multifuncionalidade dos espaços verdes produtivos e a possibilidade de articulação com infraestrutura verde. Esse conceito prevê a combinação coerente e estratégica de áreas livres conectadas, criando uma infraestrutura urbana sustentável que reoriente os usos das áreas livres urbanas. O objetivo da aplicação do conceito de CPULs é de criar espaços produtivos economicamente (através da produção de alimentos), sócio-culturalmente (gerando maior qualidade de vida) e ambientalmente (reduzindo emissão de gás carbônico, aumentando a biodiversidade e melhorando a qualidade do ar e do microclima) (Viljoen, Bohn e Howe, 2005).

$\mathrm{O}$ conceito de CPUL compreende a introdução de paisagens produtivas interligadas através de espaços livres que atravessam o ambiente construído de forma contínua, conectando os diversos tipos de áreas livres existentes no interior da cidade, relacionando, finalmente, à área rural no entorno do centro urbano. Ao contrário do que possa parecer a princípio, os CPULs não são sobre apagar o tecido urbano consolidado, mas sim de construir alternativas e superar as características inerentes à cidade, adaptando seu desenho e seu tipo a elas, numa relação de complementação não só com o espaços livres, mas com o ambiente construído também. Dentro dessa perspectiva, as características locais de cada cidade irão apresentar conjuntos específicos de possibilidades e condições, impactando na concepção e implementação desses espaços.

Essas paisagens produtivas têm como objetivo ser produtivas de diversas formas. Do ponto de vista social, pode oferecer áreas voltadas para atividades de lazer e recreação, educação ambiental e práticas esportivas. Enquanto conectores urbanos, podem compor uma infraestrutura viária voltada para pedestres e ciclistas. As paisagens produtivas também podem se articular a espaços de 
cultivo de alimentos para a população, reduzindo custos de distribuição e armazenamento da produção, e também à infraestrutura verde, que por sua vez providencia diversos serviços ecossistêmicos à cidade (proteção de biodiversidade, resiliência ambiental e urbana, melhora da qualidade da água, etc).

Os CPULs propoem espaços livres desenvolvidos para incorporar elementos vivos e naturais, projetados para permitir e estimular que moradores observem e interajam com atividades e processos tradicionalmente associados ao meio rural, restabelecendo uma relação entre a vida e os processos necessários para possibilitá-la. Esses espaços por sua vez possibilitam outros tipos de relações e interações dos sujeitos com o ambiente, que atualmente são limitadas pela escassez de áreas verdes atrativas para a população no espaço urbano.

\section{Contexto da cidade de Niterói}

Niterói é um município da Região

Metropolitana do Rio de Janeiro, com uma população de cerca de 490 mil habitantes, caracterizada por ser uma área $100 \%$ urbana. É uma cidade onde podemos observar diversas iniciativas relacionadas ao cultivo agrícola e à pecuária, como hortas comunitárias, particulares e em escolas. A primeira iniciativa de incentivo público ocorreu em 1994, com a criação do programa Hortas Comunitárias, destinado à utilização de terrenos privados voluntariamente cedidos pelos proprietários através de comodato para a agricultura urbana. O programa, no entanto, foi apenas instituído por lei, não sendo posteriormente regulamentado, significando, na prática, a inexistência do mesmo.

Em 2015, surge o Programa de Agricultura Urbana em Niterói, o Nit-Hortas, de iniciativa da Secretaria de Meio Ambiente, Recursos Hídricos e Sustentabilidade, que atualmente aguarda parecer da Procuradoria Geral do Município. Segundo a Prefeitura, o objetivo é implantar hortas comunitárias em terrenos ociosos particulares ou públicos, fortalecendo as ações comunitárias e melhorando a qualidade de vida, do meio ambiente e do espaço urbano. O programa também prevê ações de capacitação relacionadas a técnicas de agricultura urbana e sua manutenção, trabalho comunitário, proteção ambiental, entre outros, além de acompanhamento.

A agricultura urbana em Niterói ocorre principalmente nas franjas da cidade, em áreas fronteiriças aos municípios vizinhos, no caso, São Gonçalo e Maricá. Segundo o último Censo Agropecuário do IBGE, realizado em 2017, a cidade possui 16 estabelecimentos agropecuários. Esses estabelecimentos ocupam uma área de 604ha, o que corresponde a $4,51 \%$ da extensão territorial do município.

A cidade de Niterói apresenta um grande potencial para criação de uma rede de estruturas verdes, que conectem áreas verdes e ofereçam maior resiliência para a cidade. Atualmente, cerca de $33 \%$ de seu território é constituído por áreas verdes preservadas, um número expressivo considerando o contexto de cidades em regiões metropolitanas. Por possuir um grande patrimônio ambiental, se torna necessário pensar estratégias para a coexistência das áreas naturais com o ambiente construído de forma sustentável.

As unidades de conservação no município são compostas por dois tipos (Figura 1), segundo o Sistema Nacional de Unidades de Conservação: as Unidades de Conservação de Proteção Integral, que tem como objetivo a preservação integral da natureza, e as Unidades de Conservação de Uso Sustentável, que tem como objetivo compatibilizar a conservação da natureza com o uso sustentável de recursos naturais, admitindo a presença humana em suas áreas.

Outra característica relevante na cidade que poderia ser potencializada através da adoção de estratégias de desenvolvimento urbano sustentável é a questão do transporte cicloviário. Niterói possui um grande número de usuários de bicicleta, o que pode ser verificado tanto pelo grande uso das ciclovias (principalmente em horários de pico), quanto pela saturação de bicicletários e afins. $\mathrm{O}$ Bicicletário Araribóia, por exemplo, localizado ao lado da estação das barcas na Praça Araribóia, foi implementado pela prefeitura em 2017 e até o início de 2018 já possuía mais de 5 mil usuários cadastrados. O Bicicletário é um espaço público onde o usuário pode deixar sua bicicleta em segurança e possui cerca de 446 vagas - que 
lotam diariamente. Mais da metade dos usuários utiliza o espaço de 5 a 6 vezes por semana, ou seja, utiliza a bicicleta como meio de transporte para suas atividades cotidianas.

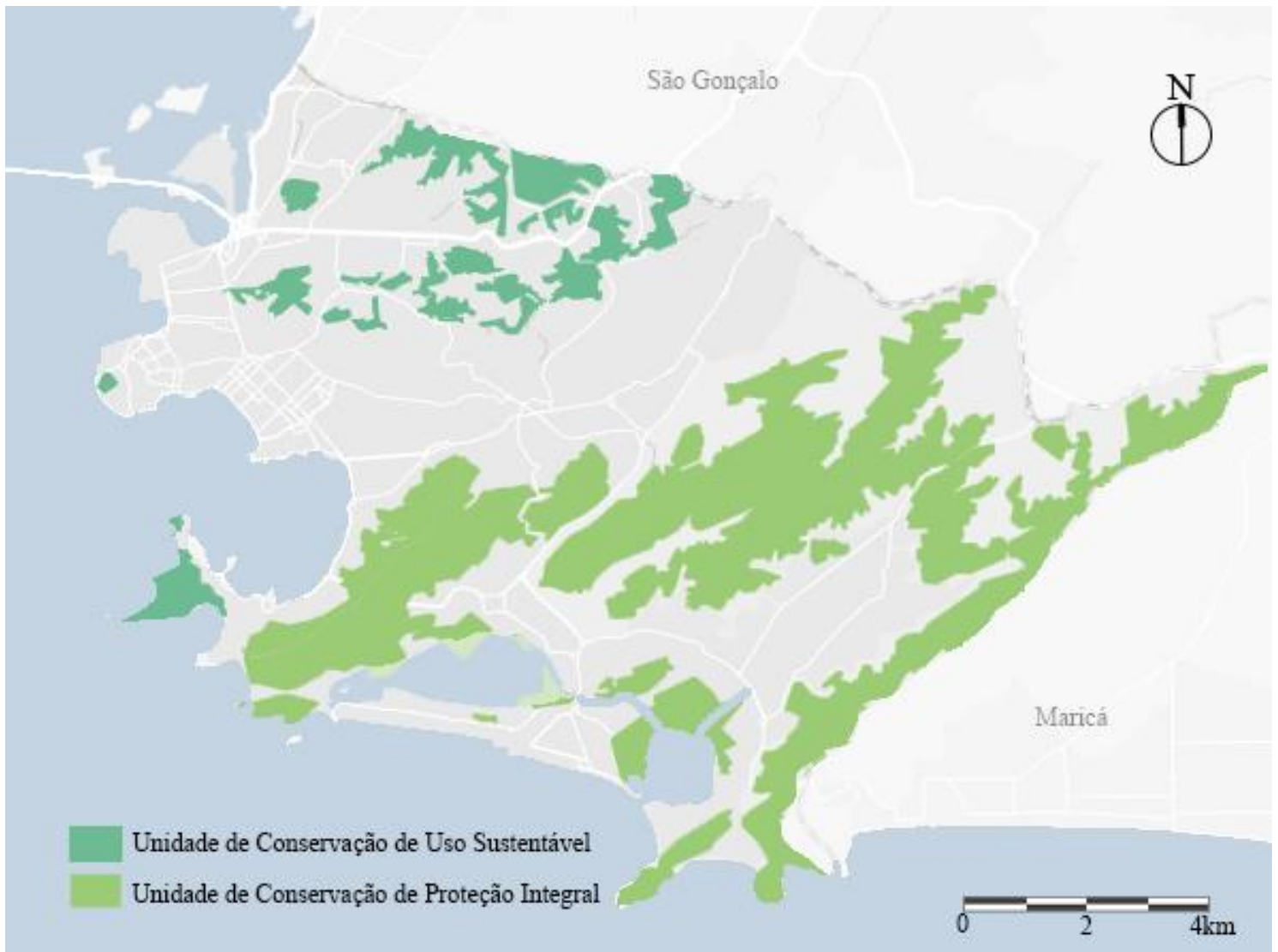

Figura 1. Mapa das Unidades de conservação do município de Niterói (fonte: elaborada pela autora, a partir de dados do Sistema de Gestão de Geoinformação da Prefeitura Municipal de Niterói).

A despeito do grande número de ciclistas, e dos diversos investimentos recentes da Prefeitura, a malha cicloviária da cidade (Figura 2) ainda é bastante escassa e desconectada, o que gera uma grande demanda de vias cicláveis. Atualmente, são aproximadamente $60 \mathrm{~km}$ de malha cicloviária, o que inclui ciclovias, ciclofaixas, ciclorrotas e calçadas compartilhadas. O objetivo da prefeitura é duplicar esse número até 2021.

A malha cicloviária da cidade ainda carece de muitas melhorias. Das poucas vias disponíveis para ciclistas, muitas não apresentam a segurança necessária aos usuários e possuem pavimentação e iluminação ruins. A falta de áreas verdes no entorno também constitui um inconveniente, já que a presença delas poderia melhorar o microclima e o sombreamento dessas áreas, tornando mais confortável e motivante o uso de bicicletas. A drenagem insuficiente em diversos pontos da cidade, que poderia ser significamente melhorada com adoção de estratégias de infraestrutura verde, também representa um problema nesse quesito, uma vez que muitas das ciclovias e calçadas apresentam grandes alagamentos nos dias chuvosos. Todos esses obstáculos também se refletem na vida cotidiana de pedestres, frutos da má qualidade e falta de planejamento do espaço público. 


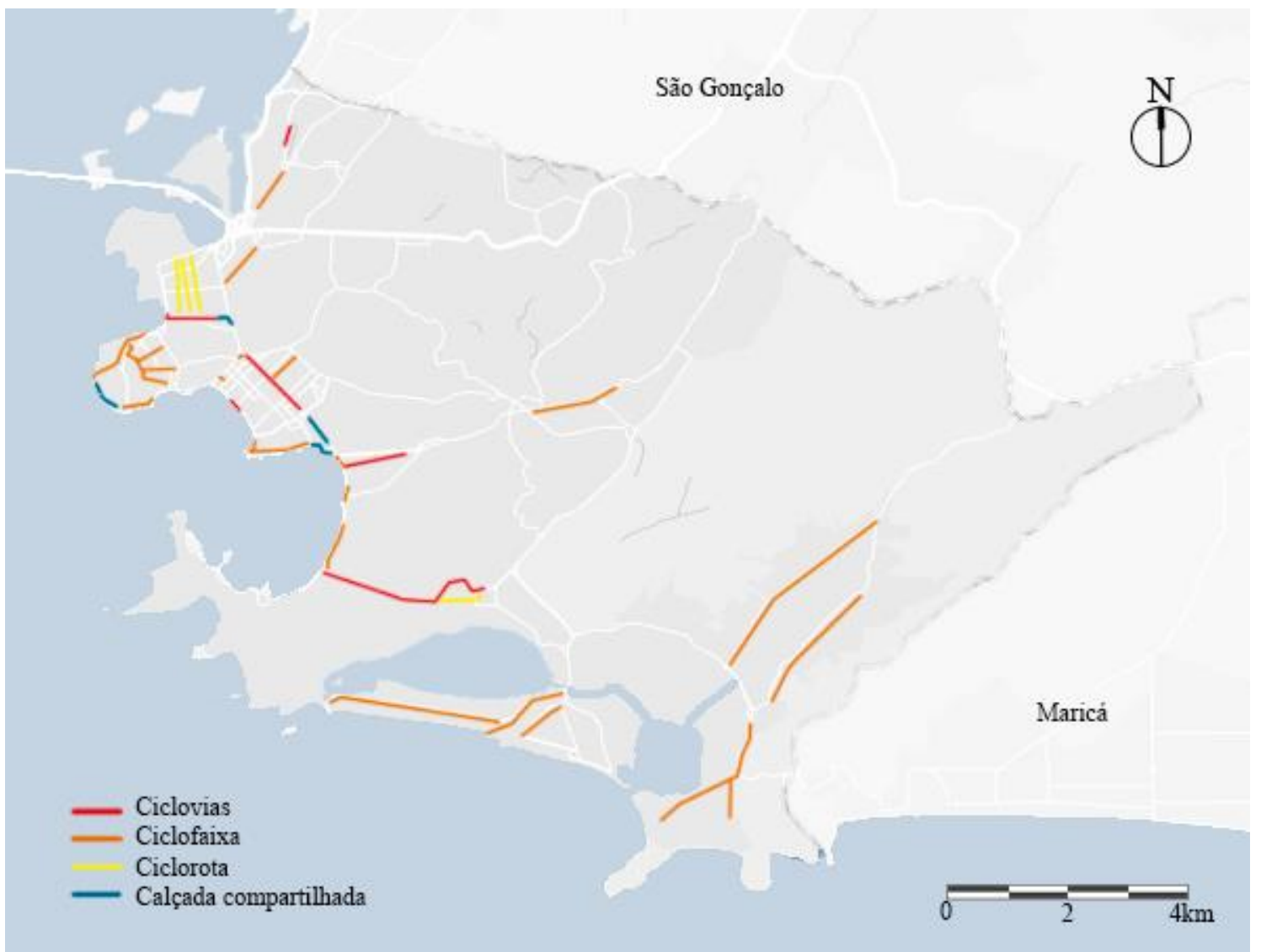

Figura 2. Mapa cicloviário de Niterói (fonte: elaborada pela autora, a partir de dados do Sistema de Gestão de Geoinformação da Prefeitura Municipal de Niterói).

São diversas as demandas e necessidades que poderiam ser supridas a partir de um planejamento integrado no território, que adote uma política pela sustentabilidade e o direito à cidade. A implementação das paisagens produtivas inspiradas pela noção de CPULs, como as hortas urbanas, poderia ser um elemento de inclusão social e educação ambiental, articulada a áreas de convívio social e infraestruturas verdes que associam paisagismo e serviços ecossistêmicos. Por último, essa rede de estruturas verdes poderia se integrar às unidades de conservação existentes no município, contribuindo positivamente para a biodiversidade e para o ecossistema da cidade.

\section{Plano de CPULs para a cidade de Niterói}

O Plano de CPULs desenvolvido tem como objetivo articular as demandas do município apresentadas com a implementação de espaços para agricultura urbana. $\mathrm{O}$ conceito de CPULs se demonstra bastante adequado para articular tais demandas, pois tem a multifuncionalidade e a combinação de usos das áreas livres como fundamento.

Com esses objetivos, se propôs a criação de uma rede de estruturas verdes multifuncionais. Tais estruturas têm como finalidade serem espaços produtivos em diversos aspectos, seja na produção de alimentos, plantas ornamentais e medicinais, seja na criação de espaços de encontros, lazer, educação, esportes e comércio, seja pela oferta de serviços ecossistêmicos, como a drenagem de águas pluviais, a melhora da qualidade do ar e do microclima.

As estruturas que integram essa rede de paisagens multifuncionais foram desenvolvidas a partir da subdivisão do objetivo geral do plano em objetivos específicos: conexões entre áreas de interesse ambiental e parques, criação de caminhos para pedestres e ciclistas, geração de áreas de cultivo de alimentos, lazer e educação ambiental. A partir desses objetivos, estabeleceu-se três tipologias de espaços públicos, propostas segundo seus principais usos e funções, e que, articuladas, integram 
uma rede de estruturas verdes produtivas: os parques-jardins, as praças produtivas e os corredores verdes.

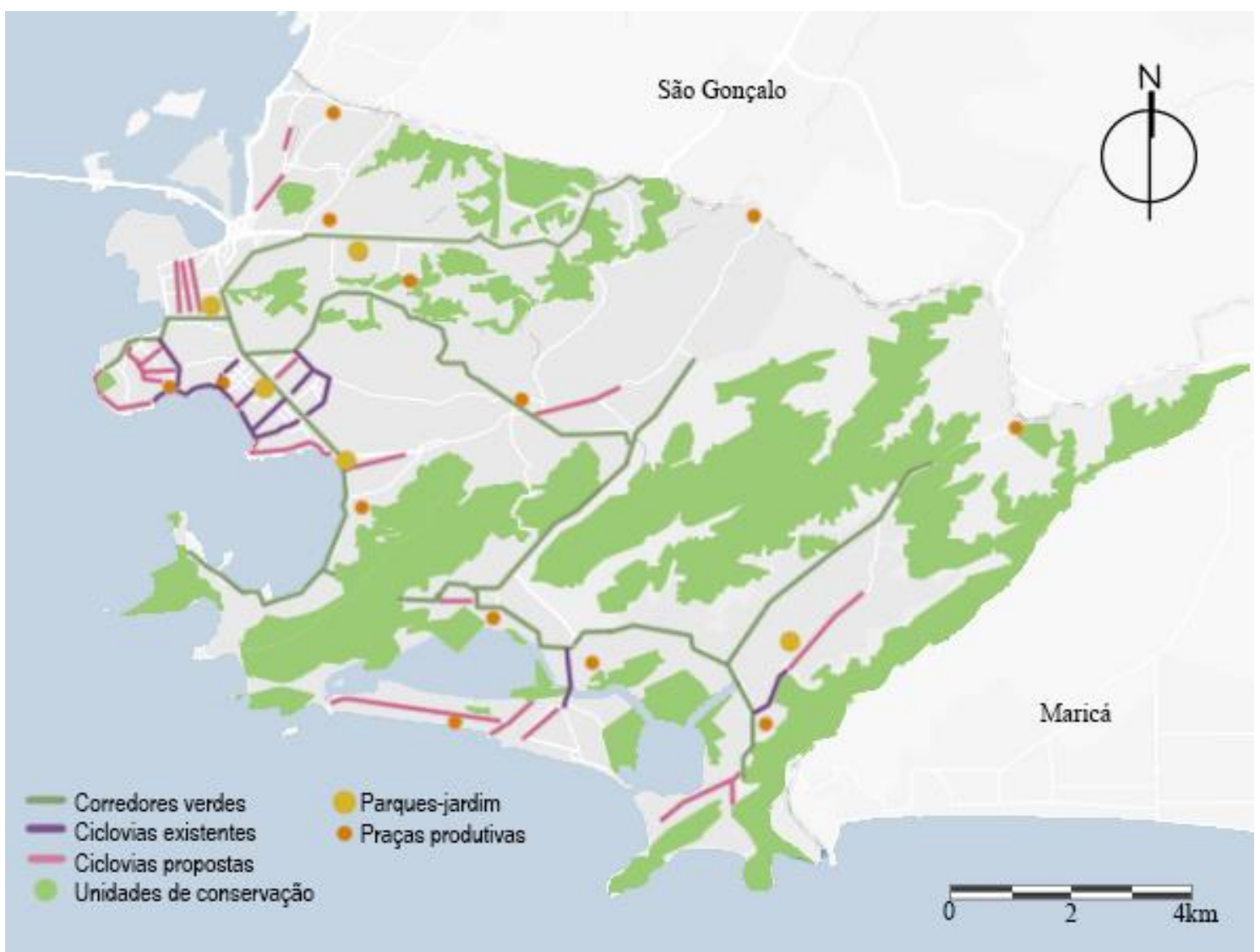

Figura 3. Mapa de áreas potenciais para implementação de CPULs (fonte: elaborada pela autora).

Com base nas reflexões apresentadas e nas tipologias propostas, foram mapeados os locais no município com potencial de implementação (Figura 3). Ao todo, foram estabelecidos 5 parques-jardim e 12 praçasprodutivas.

Os parques-jardim se caracterizam por ser grandes parques, de importância municipal, que abrigam espaços de lazer e recreação, e principalmente espaços de agricultura e voltados à educação ambiental. Podem funcionar como pólos de recursos para agricultura urbana, com fornecimento de insumos, presença de técnicos para assistir à população e canteiros para ensino e experimentação. Também podem abrigar infraestruturas verdes de maiores dimensões, como lagoas pluviais. Com base na proposta, foram selecionados parques municipais de grande extensão e que possuem uma importância significativa no contexto da cidade como um todo. Tais áreas são: o Horto do Fonseca, Horto de Itaipu, Campo de
São Bento, Parque das Águas e o Skate Park no bairro de São Francisco.

As praças-produtivas têm como objetivo suprir as necessidades locais de cada bairro, funcionando como um espaço comunitário. Podem ter áreas de lazer e esportes, espaços para encontros e eventos comunitários, hortas comunitárias e infraestrutura verde como jardins de chuva. Todo o projeto de praçaprodutiva deve estar em consonância com as dinâmicas e atividades locais, e por isso, $o$ projeto deve partir dos próprios usuários, contribuindo para a criação de sentido, identidade e apropriação do espaço. Para essa tipologia, foram escolhidas praças de bairros residenciais, prioritariamente de propriedade do município.

Os corredores-verdes seriam conectores das áreas propostas com outras áreas verdes, infraestrutura verde e unidades de conservação, proporcionando biodiversidade e criando caminhos de grande qualidade 
urbana e ambiental para pedestres e ciclistas. Para implementação dos corredores-verdes, se buscou eleger eixos viários relevantes, principalmente que acontecem ao longo de algum curso d'água, e que oferecessem a possibilidade de integração de áreas verdes e ciclovias.

\section{Considerações Finais}

A agricultura urbana pode ser uma aliada importante na promoção de cidades mais resilientes e inclusivas, com melhor qualidade de vida e maior oferta de alimentos frescos a baixo custo, gerando vitalidade e uso de espaços residuais desintegrados e subutilizados, mais áreas verdes, e portanto, contribuindo positivamente na dinâmica socioespacial da cidade. São diversos os desafios presentes na implementação de projetos voltados à agricultura urbana nas cidades brasileiras. Muitos decorrem de uma percepção de que essa atividade não desenvolve todo o potencial comercial do solo urbano, fruto da noção de que os espaços livres são elementos dispensáveis no espaço urbano. Tal percepção é equivocada e a sua hegemonia tem sacrificado de modo significativo a qualidade do espaço e da vida urbana. Romper com essa visão é fundamental para que os espaços livres passem a ser compreendidos como elementos essenciais da cidade, que não só proporcionam amenidades e áreas de "respiro", mas que também possuem um papel fundamental na qualidade da vida urbana e na resiliência do ecossistema urbano.

Dentro dessa perspectiva, a agricultura urbana como um espaço livre que gera produtos, que por sua vez podem ser explorados comercialmente pelas comunidades, pode constituir um componente com fortes argumentos para sua implementação. A partir disso, diversas outras discussões e políticas podem ser suscitadas: a respeito do desenvolvimento sustentável, da alimentação e nutrição, a apropriação de espaços públicos, a separação entre o meio rural e urbano, os espaços livres na cidade, a educação ambiental. A agricultura urbana pode ser apenas o primeiro passo de muitos por uma cidade mais justa e sustentável. Dentro do conceito de CPULs, utilizado nas reflexões apresentadas, a agricultura urbana se apresenta como apenas uma atividade agregadora, no qual a partir dela são pensados diversos outros espaços que beneficiam as pessoas, a mobilidade do pedestre e do ciclista, a prevenção de enchentes através da melhora da drenagem, as áreas de lazer e educação, em suma, uma cidade com maior qualidade de vida.

O Plano de CPULs desenvolvido aqui teve como objetivo evidenciar as possibilidades e as potencialidades de integração da agricultura urbana e outras paisagens produtivas no ambiente construído enquanto estratégia de resiliência e sustentabilidade urbana, ambiental e social. Com esse exercício, não se buscou traçar um receituário ou um modelo, mas sim apresentar como aspectos aparentemente desconexos da cidade podem ser associados e melhorados através da integração de paisagens produtivas multifuncionais.

O processo de concepção e implementação dessas áreas deve contemplar o envolvimento e a participação direta de todos cidadãos envolvidos. Como visto, já existem projetos na cidade que tem como objetivo a implementação de hortas comunitárias, porém, estes não dialogam com as práticas de agricultura urbana populares já existentes. Para que esses projetos realmente sejam apropriados pelas pessoas, é necessário que eles visem atender os anseios e as necessidades delas. Somente com um planejamento participativo, que abarque as especificidades de cada território, será possível consolidar esses projetos. Além disso, é somente com o envolvimento ativo das pessoas que será possível amplificar as discussões que podem ser proporcionadas por esses espaços.

Outro fator-chave para o sucesso de tais projetos, é a difusão de políticas articuladas em outras áreas, como a educação ambiental por exemplo. É necessário que seja adotado um conjunto de estratégias que contemplem os objetivos de uma política urbana voltada para a sustentabilidade sócio-ambiental. Através da convergência de diversas políticas multissetoriais é que se cria a possibilidade do desenvolvimento de novas relações e significações do território. É necessário que o poder público se comprometa com essas questões e com a implementação dessas políticas, sem agir, no entanto como o único tomador de decisões. É preciso que a participação da população tenha um papel central e ativo, para garantir a adesão e o envolvimento nessas políticas. 
Em Niterói, foram diagnosticadas diversas demandas que evidenciam a necessidade de incorporação de espaços públicos como ciclovias, praças para hortas comunitárias, etc. Essas demandas, além do fato da cidade ter boa parte do seu território constituído por unidades de conservação, indicam a necessidade de um desenvolvimento urbano sustentável. O que observamos recentemente é, no entanto, o contrário. Na Região Oceânica, por exemplo, a região administrativa do município com o maior patrimônio ambiental e principal área de

\section{Notas}

${ }^{1}$ Este artigo foi submetido originalmente até o prazo de 20 de julho de 2019 ao PNUM 2019 Maringá. A seleção dos artigos foi feita pelos editores desta seção temática entre 24 de agosto e

\section{Referências}

Alonso, N., Casadevante, J. (2014) A desalambrar: Agricultura urbana, huertos comunitarios $\mathrm{y}$ regulación urbanística. Hábitat y Sociedad. 7, 3152. Disponível em: https://revistascientificas.us.es/ index.php/HyS/article/view/4489 [Consultado em 08 de dezembro de 2019].

Araújo, E., Machado F. D. T. (2018) Agricultura urbana e políticas públicas: exigências da cidade contemporânea. Em: J. Rosin, N. Constantino, S. Benini (org) Cidade, resiliência e meio ambiente. Tupã, Anap, pp. 163-179.

Boukharaeva, L., Chianca, G., Marloie, M. (2007) Agricultura urbana como fenômeno universal. Em: Carvalho, S., Knauss, P. (org) Agricultura urbana: dimensões e experiências do Brasil atual. Rio de Janeiro, Enda Brasil, pp. 11-30. expansão urbana, o que é sinalizado é uma mudança do tipo de ocupação atual na área. Com a recente implementação da Transoceânica, importante eixo viário que liga a Zona Sul da cidade com a Região Oceânica, a tendência que se apresenta é de um uso mais intenso do solo com flexibilização das áreas de proteção ambiental, como as faixas marginais de proteção das lagoas de Itaipu e Piratininga.

29 de outubro de 2019. As versões revisadas foram enviadas até o dia 10 de dezembro de 2019.

${ }^{2}$ Fonte: Atlas Esgotos da Agência Nacional de Águas (2017).

Coutinho, M. N. e Costa, H. S. (2011) Agricultura urbana: prática espontânea, política pública e transformação de saberes rurais na cidade. Geografias. 7, 81-97.

Santandreu, A. e Lovo, I. C. (eds) (2007) Panorama da Agricultura Urbana e Periurbana no Brasil e Diretrizes Políticas Para Sua Promoção: Identificação e Caracterização de Iniciativas de AUP em Regiões Metropolitanas Brasileiras. Belo Horizonte, FAO/MDS/SESAN/DPSD. Disponível em: http://www.agriculturaurbana.org.br/textos/ panorama_AUP.pdf [Consultado em 08 de dezembro de 2019].

Viljoen, A., Bohn, K. e Howe J (eds.) (2005) Continuous Productive Urban Landscapes: designing urban agriculture for sustainable cities, s.l, Elsevier. 


\section{Tradução do título, resumo e palavras-chave}

Productive landscapes as strategy for sustainability and food security in cities

Abstract. Food, although a basic factor for human life, is not treated as a relevant issue in urban planning. The incorporation of productive spaces in cities could bring several environmental, economic and social benefits. Through a literature review, this paper presents reflections for the planning and design of productive public open spaces, experimented by the proposition of an urban plan for the city of Niterói. This plan is based on the concept of Continuous Productive Urban Landscapes (CPULs), which comprises agriculture as an essential infrastructure for urban life and also as an element of productive landscapes that articulate multiple uses and functions, encouraging new practices and socio-spatial relations. Finally, the role of key factors for the effectiveness of the proposed planning is discussed, such as the participation of the population and the articulation of multisectoral public policies to strengthen the effects generated by these spaces.

Keywords. urban agriculture, productive landscapes, sustainability, public space, green infrastructure.

Editores responsáveis pela submissão: Karin Schwabe Meneguetti, Renato Leão Rego e Gislaine Elizete Beloto.

Licenciado sob uma licença Creative Commons. 